\title{
ENSINO À DISTÂNCIA: SUA IMPORTÂNCIA NO DESENVOLVIMENTO PROFISSIONAL ATRAVÉS DAS UNIVERSIDADES CORPORATIVAS
}

\author{
SÃO BERNARDO DO CAMPO /SP AGOSTO/2018
}

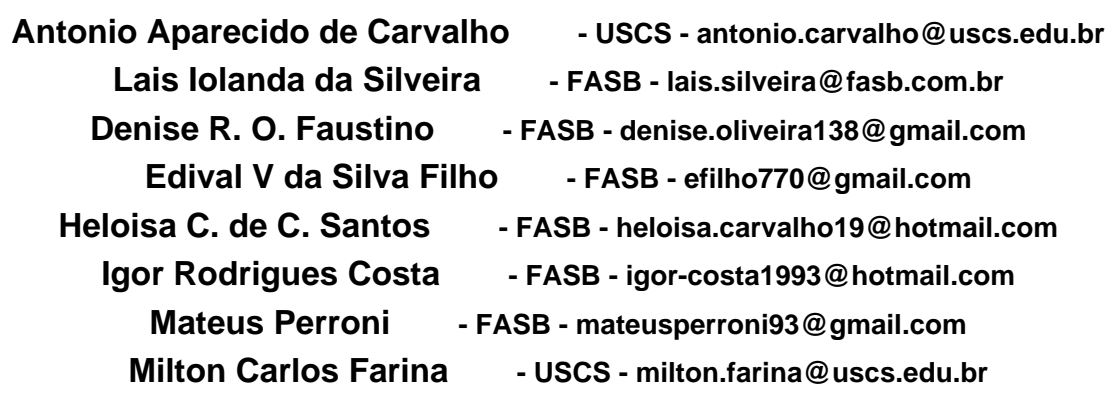

Tipo: Investigação Científica (IC)

Natureza: Relatório Final de Pesquisa

Categoria: Métodos e Tecnologias

Setor Educacional: EDUCAÇÃO CORPORATIVA

\begin{abstract}
RESUMO
A competitividade é inerente a todas as organizações e na busca por diferencial algumas empresas entenderam que o capital humano é essencial para o alcance dos resultados. As Universidades Corporativas (UCs) vem substituindo os antigos centros de treinamentos com o objetivo de desenvolver os colaboradores nas competências essenciais do negócio e não apenas para os cargos que ocupam. $O$ presente artigo buscou identificar os resultados que as UCs trazem para o desenvolvimento profissional por meio de suas práticas e métodos utilizados. A metodologia utilizada foi uma pesquisa descritiva de caráter quantitativo e o instrumento foi um questionário estruturado, cujos respondentes foram pessoas que trabalham ou já trabalharam em empresas que possuem UC. Os resultados do estudo apontaram que as UCs contribuem significativamente para o alcance dos objetivos das organizações e principalmente para o desenvolvimento profissional dos colaboradores.
\end{abstract}

Palavras-chave: Gestão de Pessoas, Treinamento e Desenvolvimento, Universidades Corporativas.

\section{AGRADECIMENTOS}

NOSSOS AGRADECIMENTOS AOS DIRETORES, DOCENTES E DISCENTES DA INSTITUIÇÃO DE ENSINO FACULDADE DE SÃO BERNARDO DO CAMPO E DA UNIVERSIDADE MUNICIPAL DE SÃO CAETANO DO SUL. 


\section{INTRODUÇÃo}

As organizações têm passado por inúmeros processos de mudanças para atenderem as necessidades dos clientes, bem como para se adaptarem ao mercado globalizado. Neste cenário elas devem se posicionar de maneira proativa, readequar sua estrutura e seus processos para serem competitivas. O ambiente interno das organizações é impactado pelo ambiente externo e dessa forma para acompanhar as exigências da competitividade é preciso desenvolver os colaboradores, devido às necessidades de aprimorarem os seus conhecimentos, habilidades e competências. A gestão de pessoas é responsável pelo estabelecimento de políticas e práticas que são imprescindíveis na condução dos assuntos relacionados com as pessoas no que diz respeito à capacitação, investimento em educação, treinamento, desenvolvimento e carreira.

A Educação Corporativa diz respeito a um programa de educação e desenvolvimento utilizado pelas empresas com objetivo de desenvolver os colaboradores e parceiros do negócio nas competências relacionadas às estratégias da organização. Esse assunto vem crescendo à medida que as empresas percebem a importância do desenvolvimento de pessoas e com isso a área de Treinamento e Desenvolvimento estabelece a Educação Corporativa por meio das Universidades Corporativas (UCs).

A pesquisa abordou a seguinte questão problema: Qual a contribuição das UCs para o desenvolvimento profissional dos colaboradores? Com objetivo de identificar os resultados que as UCs trazem para o desenvolvimento profissional por meio de suas práticas e métodos utilizados. Os objetivos específicos foram: Avaliar sob a ótica dos gestores os resultados práticos que a implantação da UC traz para o desenvolvimento dos profissionais e avaliar sob a ótica dos colaboradores os resultados dos treinamentos dos quais participaram por meio da UC.

\section{REFERENCIAL TEÓRICO}

Maximiano (2011) explica que nas Teorias de Taylor, Fayol e Weber o pensamento principal foi a execução dos processos e as pessoas eram colocadas em segundo plano e avaliadas como "recursos de produção" e a partir da Teoria Comportamental que surgiu uma preocupação com o bem estar delas.

Vergara (2007) afirma que na sociedade da informação surgiu a valorização das pessoas, passando a ser consideradas "geradoras de recursos" (p.25). Conforme Dutra (2002), a forma de gerir pessoas nas organizações vem passando por transformações, pois há um esforço em repensar o papel das pessoas e das organizações nas relações 
de trabalho. Com isso, o papel das pessoas vem se tornando cada vez mais importante e a organização deve proporcionar um melhor ambiente de trabalho e uma comunicação adequada. Explica que é como uma balança que busca o equilíbrio, tanto as pessoas, quanto as organizações devem estar alinhadas em prol desta busca e que os processos de gestão de pessoas atuam para garantir a manutenção deste equilíbrio. Para esse autor a Gestão de Pessoas (GP) é classificada em três processos: 1) Movimentação: compreende as práticas de captação, internalização, transferências, promoções, expatriação e recolocação; 2) Valorização: remuneração, premiação, serviços e facilidades e 3) Desenvolvimento: capacitação, carreira e desempenho. Neste estudo o processo enfatizado diz respeito ao desenvolvimento das pessoas, o qual engloba as Universidades Corporativas, como ações de desenvolvimento formais.

Segundo Gil (2001), o treinamento é o conjunto de experiências de aprendizagem centradas na posição atual da organização. Trata-se de um processo de curto prazo para melhorar o desempenho das pessoas em suas atividades relacionadas ao cargo. 0 desenvolvimento é um processo de aprendizagem não relacionado diretamente ao cargo, por ser um modelo voltado à educação em longo prazo.

A realidade das organizações mudou e surgiu a necessidade que os colaboradores contribuam de forma efetiva nos resultados do negócio. Organizações que tem centros de treinamento e desenvolvimento (T\&D) buscam aprimorar os métodos de aprendizagem e entendem a importância do desenvolvimento do conhecimento e competência dos seus colaboradores. Com isso, necessitam renovar os seus centros de T\&D, de modo que estejam alinhados a contribuir com a eficácia e o sucesso para a estratégia empresarial. "A missão da educação corporativa consiste em formar e desenvolver talentos na gestão dos negócios, promovendo a gestão do conhecimento, através de um processo de atividade ativa e contínua" (EBOLI, 2002, p. 194).

Ferreira (2012), afirma que algumas organizações começaram a utilizar a Educação Corporativa com o intuito de melhorar a capacidade de cada colaborador para a tarefa empresarial e que algumas funções para serem executadas com êxito, necessitam de treinamentos específicos. Para Gdikian e Silva (2002), as UCs têm por finalidade a educação e o desenvolvimento da cadeia de valor que envolve colaboradores, fornecedores, clientes, acionistas, etc. Objetivam atender as estratégias empresariais para desenvolver novas oportunidades, entrar em novos mercados e estreitar relacionamentos com os clientes.

De acordo com Silva (2009), o conteúdo trabalhado pela UC se relaciona a crenças, valores, cultura da organização e, sobretudo o conhecimento sobre o negócio. Eboli 
(2002) enfatiza que o principal objetivo da Universidade Corporativa é o desenvolvimento e a instalação das competências organizacionais e humanas, competências que são críticas para o alcance das estratégias de negócio. Afirma que a implantação de projetos bem sucedidos baseia-se em 8 práticas: Prática 1: para estabelecer o elo entre o desenvolvimento de competências dos colaboradores e as estratégias de negócio é preciso focar na identificação, formação e a mobilização dessas competências. Prática 2: o sistema de gestão do conhecimento estimula o compartilhamento de conhecimentos e a troca de experiências como fonte de vantagem competitiva. Prática 3: utilização da tecnologia aplicada à educação. "Aprendizagem a qualquer hora e em qualquer lugar", através de recursos como a aprendizagem virtual que permite o uso dos conteúdos à distância. Prática 4: forte compromisso da organização com a cidadania empresarial: exercitar a cidadania tem se mostrado uma das ferramentas mais eficazes no desenvolvimento de colaboradores. Prática 5: um dos principais veículos de consolidação e disseminação da cultura empresarial Prática 6: líderes e gestores se responsabilizam pelo processo de aprendizagem: a importância de serem referências para as pessoas da organização. De acordo com Eboli (2005), quanto mais eles se envolverem como educadores maiores serão as chances do ensino ser eficaz, pois exercem papel de influência. Prática 7: avaliação dos resultados. Devido à ineficácia dos programas e o aumento da competitividade e da crise econômica, as organizações necessitam avaliar os custos com os treinamentos realizados. Prática 8: formação de parcerias com instituições de Ensino Superior: a UC é uma alternativa para quem trabalha e busca um curso superior, assim as parcerias podem trazer benefícios em termos de custos e viabilidade.

Segundo Gdikian e Silva (2002), a Educação Corporativa passou a subverter o modelo tradicional de educação por meio da internet e com isso as organizações transferiram a responsabilidade do aprendizado para o aluno. Além da economia, o ensino virtual transforma o conhecimento e o capital intelectual dos colaboradores nos principais ativos das organizações, pois a web torna possível disseminar e treinar as pessoas numa velocidade jamais imaginada. Isso permite ao colaborador conquistar autonomia e flexibilidade para buscar novos conhecimentos. Silva (2009) explica que foi nas empresas que a EAD cresceu e a Educação Corporativa teve sua expansão, atendendo mais pessoas do que na educação presencial. Estima-se que $50 \%$ das empresas que possuem UC utilizam a EAD como suporte para a realização de seus cursos. Para Andrade e Tachizawa (2003), com o advento e expansão da internet, dos recursos multimídias, das telecomunicações e a convergência dessas mídias, foi possível implementar formas alternativas de UCs, propiciando o desenvolvimento de programas de EaD e a criação de fornecedores com soluções educacionais. 


\section{PROCEDIMENTOS METODOLÓGICOS}

Para o levantamento de dados foi realizada pesquisa quantitativa de caráter descritivo, com aplicação de questionários com 16 perguntas fechadas, sendo 4 para a caracterização do respondente e 12 relativas à Universidade Corporativa. Utilizou-se uma escala de 6 níveis de 0 a 5 , em que quanto mais próximo de 5 , representou a realidade da organização e quanto mais próximo de 0 , não se tratava da realidade. Com base nos dados estatísticos foram calculadas as médias de cada questão abordada, resultado acima de 2,5 indicou uma tendência positiva à realidade vivenciada pelo participante e abaixo de 2,5 tendência negativa quanto à realidade, a média de 2,5, indica que os respondentes ficaram em dúvida em relação à tendência, se esta é positiva ou negativa. Os sujeitos de pesquisa do estudo foram pessoas que trabalham ou que já trabalharam em empresas que possuem UC's, sendo assim justifica-se o uso de amostragem não probabilística do tipo intencional. O número da amostra foi obtido com base nacional, por isso o mínimo de informantes necessários deveria ser 385 e alcançou-se 422 no final da coleta dos dados. A coleta dos dados foi por meio da internet, utilizando-se um formulário eletrônico no Google Forms, através de um link e compartilhando nas redes sociais.

\section{APRESENTAÇÃO E DISCUSSÃO DOS RESULTADOS:}

4.1 Perfil da Amostra: Sobre o perfil dos respondentes $51,9 \%$ são do gênero masculino; em relação ao cargo, os gestores representam $43,4 \% \%$. Quanto ao ramo de negócio, 61,6\% são de "serviços" e sobre a participação nas UCs (tabela 1), 73,5\% participa no próprio local de trabalho, considerando os que assinalaram mais de uma alternativa. 
TABELA 01 - Participação na Universidade Corporativa

\begin{tabular}{lccc}
\hline Participação na Universidade Corporativa & $\begin{array}{c}\mathbf{n} \\
\text { (amostras) }\end{array}$ & $\begin{array}{c}\mathbf{f} \\
\text { (\%) }\end{array}$ \\
\hline No local de trabalho & 130 & 30,8 \\
\hline Ensino a distância (EAD) & 47 & 11,1 \\
\hline Em parceria com outra instituição de ensino & 55 & 13,0 \\
\hline Ensino a distância (EAD) e em parceria com outra instituição & 10 & 2,4 \\
\hline No local de trabalho e em parceria com outra instituição & 28 & 6,6 \\
\hline No local de trabalho e ensino a distância (EAD) & 64 & 15,2 \\
\hline No local de trabalho, EAD e em parceria com outra instituição. & 88 & 20,9 \\
\hline Total & 422 & 100 \\
\hline
\end{tabular}

Fonte: Pesquisa de campo (2017). aprendizagem.

GRÁFICO 1: divulgar e reforçar a importância dos programas de

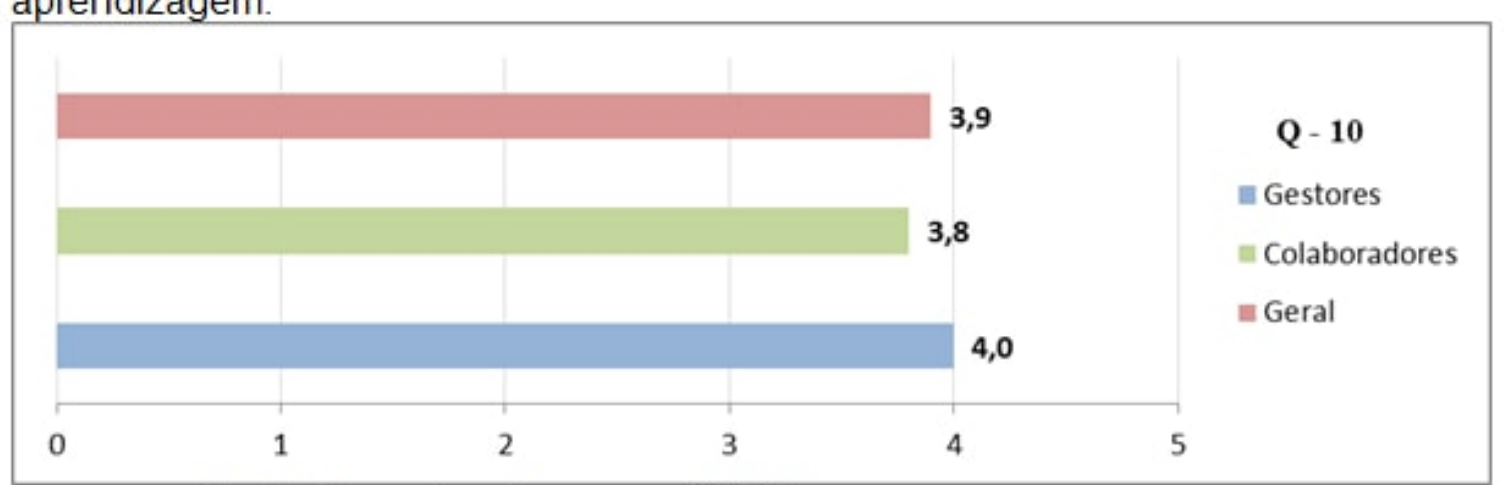

Fonte: Pesquisa de campo (2017).

Sobre a divulgação e reforço da importância dos programas de aprendizagem, a amostra geral e os colaboradores indicam que existe uma tendência para tornar-se realidade nas empresas. Quanto aos gestores, os resultados apontaram que se trata de uma prática nas organizações. 

aprendizagem.

GRÁFICO 2: Comprometimento dos líderes e gestores no processo de

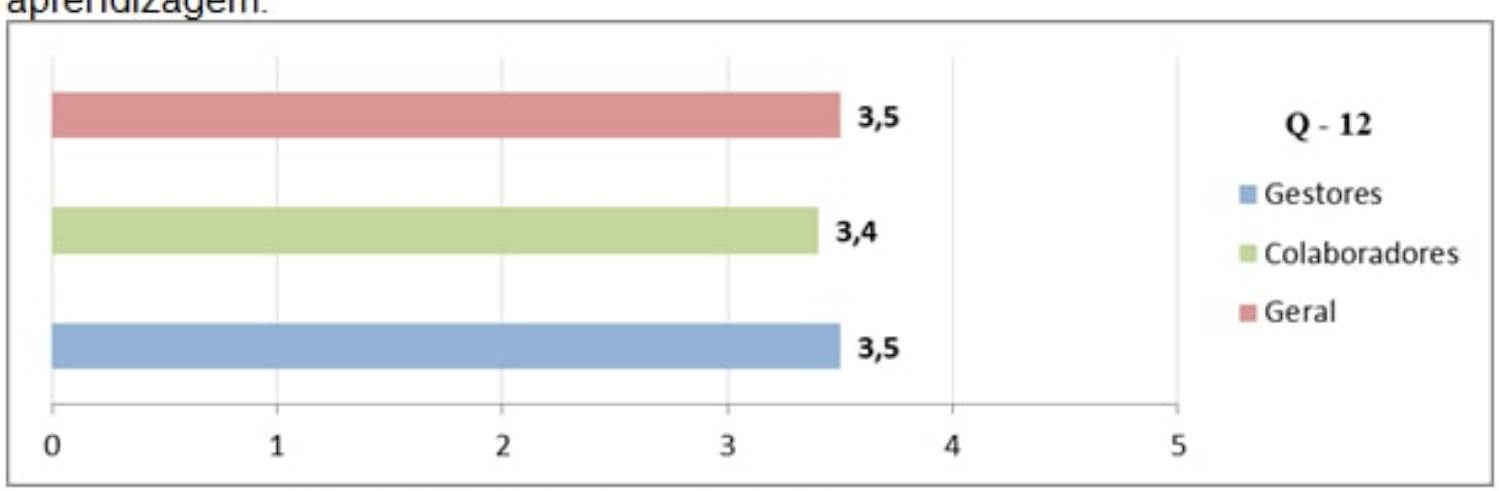

Fonte: Pesquisa de campo (2017).

Todos os respondentes afirmativamente apontaram que o incentivo e a responsabilidade pelo processo de aprendizagem por parte dos líderes se inclinam a ser realidade.

GRÁFICO 3: expectativas dos colaboradores.

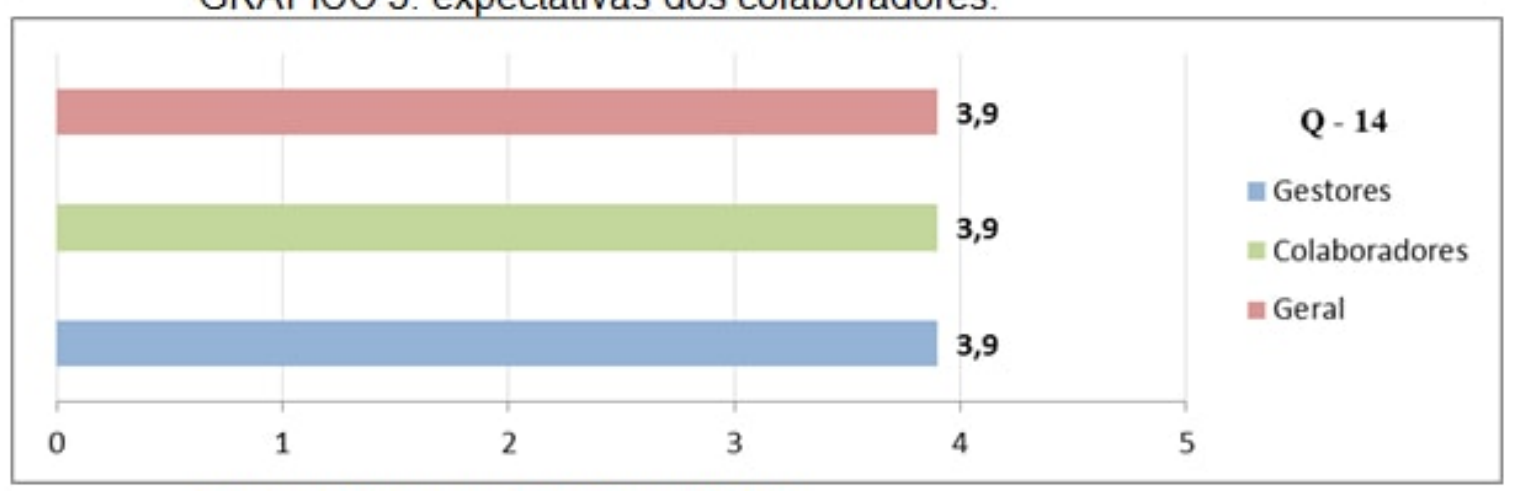

Fonte: Pesquisa de campo (2017).

Os resultados alcançados por intermédio da UC atendem as expectativas dos respondentes, pois confirmam ser fato nas empresas.

GRÁFICO 4: líderes e gestores são importantes no processo de aprendizagem.

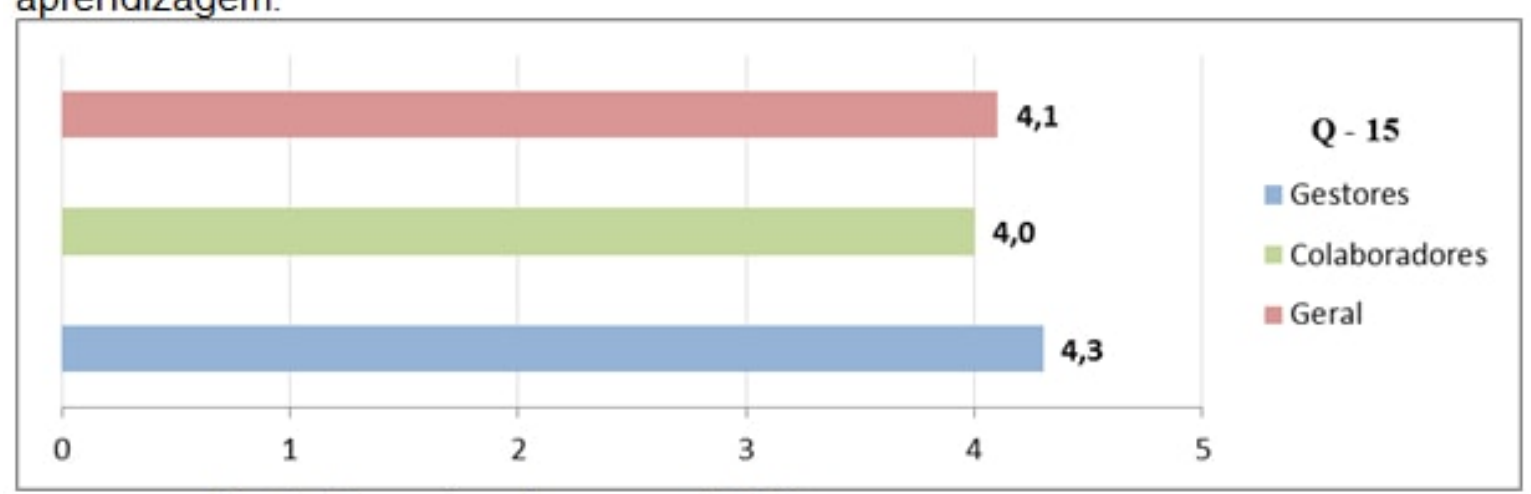

Fonte: Pesquisa de campo (2017). 
Todos consideram que os líderes e os gestores tem papel importante no processo de aprendizagem e desenvolvimento de suas equipes.

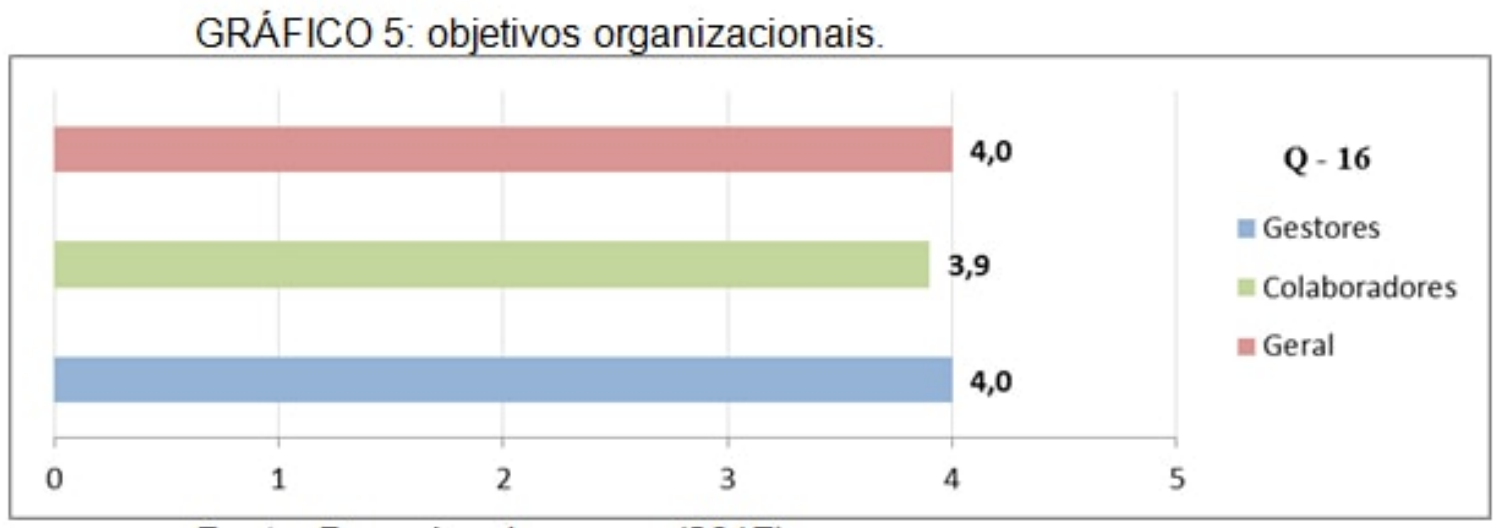

Fonte: Pesquisa de campo (2017).

A amostra geral e os gestores, apontaram que na realidade das empresas, os treinamentos aplicados na UC atingem os objetivos organizacionais; para os colaboradores (média de 3,9), há uma tendência positiva de ser realidade nas organizações.

\section{CONSIDERAÇÕES FINAIS}

Foi possível constatar na pesquisa que os colaboradores e os gestores acreditam que as UCs a distância contribuem para o desenvolvimento e identificação das competências tanto para o aspecto humano, quanto para o negócio.

O estudo abordou a utilização do conhecimento no dia a dia das organizações, através de uma troca de experiências e aprendizado; com base nos resultados obtidos todos os respondentes vivenciam essa troca de conhecimento nas organizações, confirmando o pensamento de Silva (2009) que trata a gestão do conhecimento como uma maneira de olhar a organização para obter vantagem competitiva, pois o conhecimento é o fator mais importante na competição organizacional da atualidade e deve ser inserido em cada processo, operando como parte das atitudes dos colaboradores.

No que diz respeito ao uso da tecnologia e a aprendizagem, o ensino à distância é uma ferramenta fundamental no aprendizado contínuo dos colaboradores e os resultados indicaram que $49,53 \%$ dos respondentes já participaram de UC por meio do ensino à distância.

Sobre a UC ser veículo de disseminação da cultura, verificou-se que há uma tendência a ser realidade nas organizações, média de 3,9 na amostra geral, assim como na visão 
dos gestores a mesma afirmativa é uma realidade com a média 4,0, constatando sua contribuição e estímulo ao desenvolvimento de uma cultura de aprendizagem e autodesenvolvimento contínuo.

Em relação à questão que trata sobre a importância dos líderes tornarem-se referência nos programas de aprendizagem, os dados apontaram que eles são imprescindíveis em todo o processo de desenvolvimento apresentando média geral 4,1, constatando que há uma tendência a ser realidade em relação ao comprometimento e compromisso. Eboli (2002), recomenda que os responsáveis pelo desenvolvimento de programas educacionais desenvolvam programas e ações especificamente voltados à meta de estimular líderes a refletir sobre comportamentos e ações com suas equipes no cotidiano de trabalho.

Eboli (2002), Gdikian e Silva (2002) compartilham da ideia de que as parcerias entre organizações e instituições de ensino superior privado são benéficas. Constatou-se que as parcerias com instituições de ensino são práticas vivenciadas pelas organizações, pois $13 \%$ da amostra geral têm os treinamentos através dessas parcerias, além disso, identificou-se que mesmo as empresas que utilizam a UC no próprio local de trabalho ou por ensino a distância também possuem parcerias, representando $29,8 \%$ da amostra. Esses resultados indicam que mesmo as empresas que possuem suas próprias instalações de UC, precisam desenvolver parcerias, pois em determinado momento 0 espaço torna-se insuficiente para atender um grande número de pessoas.

Os dados demonstram que as empresas utilizam o Ensino à Distância nas Universidades Corporativas como estratégia para trazer benefícios mútuos para as empresas e colaboradores, pois as UCs funcionam como laboratórios de aprendizagem, os conteúdos ministrados são aderentes às necessidades das empresas para atender as mudanças do mercado onde estão inseridas. Os colaboradores ao participarem dos programas oferecidos pelas UCs têm suas habilidades e competências desenvolvidas, possibilitando exercer com maior autonomia e competência as suas atividades diárias. A capacitação ainda favorece a empregabilidade do colaborador no mercado de trabalho possibilitando uma atuação empreendedora.

\section{REFERÊNCIAS}

DUTRA, Joel Souza. Gestão de Pessoas: modelo, processos, tendências e perspectivas. 1. ed. São Paulo: Atlas, 2002. 210 p.

EBOLI, Marisa. O desenvolvimento das pessoas e a educação corporativa. In As 
pessoas nas organizações. FRANÇA, Ana Cristina Limongi; ARRELLANO, Elite Bernal (Orgs.). São Paulo: Atlas, 2002. 306 p.

EBOLI, Marisa. RAE - Revista de Administração de Empresas. São Paulo, 2005. Disponível em: http://bibliotecadigital.fgv.br/ojs/index.php/rae/article/viewFile/37316/36079. Acesso em 9 Mai. 2017.

GDIKIAN, Elizabeth Ayres; SILVA, Moises Correia da. Educação estratégica nas organizações: como as empresas de destaque gerenciam o processo de educação corporativa. São Paulo: Qualitymark, 2002. 96 p

GIL, Antônio Carlos. Gestão de Pessoas: Enfoque nos papéis profissionais. 1. ed. São Paulo: Atlas, 2001.307 p.

LARUCCIA, Mauro M. Impacto da Universidade Corporativa nas Organizações. Revista de Administração da Unimep. 2011, v.9. Disponível em http://www3.redalyc.org/articulo.oa?id=273719431008. Acesso em 26 Mar. 2018.

MAXIMIANO, Antonio César Amaru. Introdução à Administração. 8aㅡ ed. São Paulo: Atlas, 2011.

SILVA, Robson Santos da. A educação corporativa: universidades corporativas. In Educação à distância: o estado da arte. LITTO, Frederic Michael; FORMIGA, Marcos Maciel (org.). São Paulo: Pearson Education do Brasil, 2009. 461 p.

TACHIZAWA, Takeshy; ANDRADE, Rui Otávio Bernardes de. Tecnologia da Informação Aplicada às Instituições de Ensino e às Universidades Corporativas. São Paulo: Atlas, 2003. 248 p.

VERGARA, Sylvia Constant. Gestão de Pessoas. 6. ed. São Paulo: Atlas, 2007. 213 p. 